\title{
Obstacles to the Use of Estrogen Replacement Therapy in Women of Lower Socioeconomic Levels
}

\author{
R. Lawrence Magruder, $M D$
}

The value of estrogen replacement in postmenopausal women is well documented. Estrogen prevents or modifies the disease course of osteoporosis, ${ }^{1}$ coronary artery disease, ${ }^{2-4}$ and atrophic vaginitis, and it often is used to treat urinary incontinence. The role of estrogen replacement in prevention of strokes is more controversial; some studies suggest a positive role ${ }^{5}$ and others suggest no role. ${ }^{6}$ Recent studies indicate estrogen might have a positive effect on memory. ${ }^{7}$ Although documented risks exist, for most women the risk-benefit ratio strongly favors estrogen use after menopause. Nevertheless, despite the favorable risk-benefit ratio, studies document rates of estrogen use as low as 30 percent among postmenopausal women who are candidates for estrogen therapy. ${ }^{8}$

Even though many studies document predictors of which women are more or less likely to use estrogen, few researchers have asked the women themselves why they chose not to use estrogen, particularly women in lower socioeconomic groups. In 1987 Ravnikar $^{8}$ documented fear of cancer as the most common reason women discontinued estrogen replacement. In 1988 Ferguson et $\mathrm{al}^{9}$ concluded that fear of a return of menstrual periods was the most unfavorable factor in the decision to use estrogen replacement. In 1996 Handa et $\mathrm{al}^{10}$ found the strongest predictor of estrogen use in the Piedmont region of North Carolina to be socioeconomic status, with higher rates of estrogen use associated with higher socioeconomic status. Fear of cancer was not directly addressed in

Submitted, revised, 15 April 1998.

From the Wichita Falls Family Medicine Residency, The University of Texas Southwestern Medical School at Dallas. Address reprint requests to $\mathrm{R}$. Lawrence Magruder, $\mathrm{MD}, \mathrm{Wi}_{\mathrm{i}}$ chita Falls Family Medicine Residency, 1301 Third St, Wichita Falls, TX 76301.

This article was supported by Grant No 5-D15PE56003 from the Division of Medicine of the Health Resources and Services Administration (HRSA). Its contents are solely the responsibility of the author and do not necessarily represent the views of HRSA. the Handa study. None of the three studies listed above was limited to women of lower socioeconomic levels.

I hypothesized that women who do not use estrogen are less likely to know the effects of estrogen on their bodies or believe that estrogen has beneficial effects. With this study, therefore, I sought to answer two questions: (1) Why do postmenopausal women of lower socioeconomic standing choose not to use estrogen replacement? (2) Compared with women who do use estrogen, what differences in the knowledge of the effects of estrogen might be factors in a woman's decision not to use estrogen?

\section{Methods}

This study used a cross-sectional design. The target population consisted of women 50 years old or older who sought care from a community-based family practice residency in Wichita Falls, Tex, between 1 November 1996 and 10 January 1997. The office serves a large population of patients who do not have insurance or who are insured through a government-sponsored health plan (Medicaid, Medicare, and county indigent programs.) A few patients were insured privately. All women seeking care at the residency who met the inclusion criteria were asked to fill out the questionnaire, which was provided in both English and Spanish. Women still menstruating who were not on hormone replacement and women with an active or a history of a known medical contraindication to estrogen replacement therapy, including breast cancer, endometrial cancer, other gynecologic malignancy, or thromboembolic disease, were excluded from the study.

A questionnaire was developed from information gained by asking postmenopausal patients why they do not use estrogen replacement. Fellow clinicians also contributed possible reasons for nonuse of estrogen replacement from statements made by their patients, and female office staff contributed suggestions on questions and format. 
Table 1. Reasons Women Gave for Not Taking Estrogen Replacement.

\begin{tabular}{lc}
\hline Reason & Mean Score \\
\hline Fear of cancer & 1.5 \\
Not good for health & 1.6 \\
Take too many pills already & 1.8 \\
Cost too much & 1.9 \\
Menstruation will return & 2.1 \\
Fear breast tenderness & 2.4 \\
Race does not need it & 2.7 \\
Smoking concerns & 2.7 \\
Friends do not take it & 2.8 \\
\hline
\end{tabular}

* On a Likert scale from 1 to 4 or 5 , in which the lower numbers indicate a greater degree of concern.

Seven family physicians in academic medicine reviewed the instrument and made further suggestions. The questionnaire underwent pilot testing on members of the target population and was further modified to make it easier to use. Language was appropriate for a fourth-grade reading level.

The first portion of the questionnaire asked the respondents about their attitudes and knowledge concerning the effects of estrogen use after menopause. This section asked women to score their opinion of the effect of estrogen on the following areas; (1) bones, (2) heart, (3) breasts, (4) pelvic organs, (5) sexual desire, (6) pain with sex, (7) risk of breast cancer, (8) risk of endometrial cancer, and (9) overall health after menopause. The women were allowed to answer "don't know" to these questions. All the respondents were asked to complete this portion of the questionnaire, and the responses of women taking estrogen were compared with those of nonusers.

The second portion of the questionnaire asked those women not taking estrogen replacement specific questions why they did not. The respondents were asked to score the importance of the following categories in their decision not to use estrogen: (1) cost, (2) fear of getting cancer, (3) a perception that estrogen was good or not good for their individual health, (4) concern that menstruation would return, (5) concern that they were taking too many pills, (6) influence of friends who did not take estrogen, (7) a perception that members of her race did not need to take estrogen, (8) concern about developing breast tenderness, and (9) concern about health risks of combining estrogen replacement with smoking. In addition, the women
Table 2. Percentage of Women Who Did Not Know the Effects of Estrogen.

\begin{tabular}{lc}
\hline Area & Not Know \\
\hline Bone & 66 \\
Heart & 64 \\
Breast & 62 \\
Pelvic organs & 62 \\
Overall health & 51 \\
Sexual desire & 55 \\
Pain with sex & 72 \\
Uterine cancer risk & 72 \\
Breast cancer risk & 79 \\
\hline
\end{tabular}

were given the opportunity to write in any additional factors in their decision not to use estrogen. Mean and median values were calculated for each listed reason, and the reasons were then arranged in rank order. The lowest mean or median score indicated the greatest concern.

The questionnaire used both true-false responses and responses scored on 5-point and 4point Likert scales for a total of 28 variables. (The full questionnaire is available upon request.) Demographic and other information, including the respondent's date of birth, race, whether she had a uterus, and type of insurance coverage, if any, was extracted from the respondent's chart.

\section{Results}

A total of 52 women who met the inclusion criteria sought care during the study period. Forty-seven returned a questionnaire for a response rate of 90.4 percent. Of the women taking part in the study 34 percent were taking estrogen replacement and 64 percent were not. One woman did not respond to this question.

In those women not taking estrogen, the most important reason given was fear of cancer. The ranking of the reasons for not taking estrogen is displayed in Table 1. The only difference in order of reasons for not taking estrogen when ranked by means or medians was that the last two reasons were reversed.

The responses of estrogen users to the first part of the questionnaire concerning knowledge about estrogen were compared with the responses of nonusers. Statistical analysis using the Student's ttest failed to show a significant difference in the responses of the two groups; therefore, the data are presented with both groups combined. No associa- 
Table 3. Women's Opinions About Effects of Estrogen Replacement on Their Bodies.

\begin{tabular}{lccccc}
\hline Area & Very Good \% & Good \% & None \% & Bad \% & Very Bad \% \\
\hline Bone & 13 & 60 & 7 & 13 & 7 \\
Heart & 6 & 50 & 44 & 0 & 0 \\
Breast & 0 & 47 & 35 & 12 & 0 \\
Pelvic organ & 12 & 40 & 33 & 13 & 0 \\
Overall health & 19 & 67 & 10 & 0 & 5 \\
Desire & Increase & & No Effect & & Decrease \\
& 32 & 53 & & 16 \\
Pain with sex & Cause & & No Effect & & Stop \\
& 17 & 67 & & 17 \\
Uterine cancer & No Increase & & Small Increase & & 11 \\
Breast cancer & 44 & 64 & & 13 \\
\hline
\end{tabular}

tions were found between estrogen use and any of the demographic factors or age, race, or presence of a uterus. "Don't know" was the most common response to each of the questions about the effect of estrogen. Between 51 and 79 percent of the responses for each question were "don't know" (Table 2).

Of those women who expressed an opinion about the effect of estrogen, most answered that estrogen had a positive or no effect. At no time did the combination of bad and very bad approach more than 20 percent (Table 3 ).

The mean response for women who did and did not take estrogen was calculated for each question and compared using the Student t-test after the "don't know" responses were eliminated. In all cases there was no significant difference between the responses of those women who took estrogen and those who did not. The data were then collapsed into three categories of good, no effect, or bad and reanalyzed using a chi-square test. No significant associations were found.

\section{Discussion}

The respondents' low rate of estrogen use is consistent with findings of previous studies, as is their fear of cancer as the most important reason for not taking estrogen. Lack of knowledge of the effects of estrogen appears to be a primary factor in the reluctance to use estrogen. At least one half and at times up to 79 percent of women answered that they did not know the effect of estrogen on their bodies, which indicates physicians are not providing enough information or there was insufficient comprehension of this information for women to make an informed choice about taking estrogen replacement.

This study is limited by the short period during which data were collected and the resulting few participants. It is possible that the responses might be distributed differently had the data been collected during a longer period.

Restricting the study to women seeking care from a residency program is a limiting factor. Women of lower socioeconomic status who receive care from private physicians might answer differently. Further study to compare the knowledge base of women in better socioeconomic conditions with the knowledge base of these women is also indicated.

This study illuminates the need for physicians to clarify the role of estrogen replacement for their female patients, particularly those in lower socioeconomic groups. Ravnikar's study ${ }^{8}$ in 1987 found that only 30 percent of candidates for estrogen replacement were using estrogen. This study, done a decade later, found the same rate of estrogen usage. Ravnikar found fear of cancer to be the most commonly listed reason for women not to use estrogen replacement. This study found the same result. Medical practice in this area has advanced considerably in a decade, and physicians need to educate their patients, both with direct discussion and educational handouts. It might be necessary for family physicians to address the issue of estrogen replacement at each visit with their postmenopausal patients. Rates of estrogen use in postmenopausal women will not increase as long as one half to two thirds of women do not know how estrogen affects their bodies. Further studies 
to clarify the most effective educational methods are warranted.

The staff and 1996-97 fellows of the Faculty Development Center in Waco, Tex, helped with this study, Ron Bradshaw, MD, Cindy Passmore, MA, and William Mygdal, EdD, provided assistance in the design, statistical analysis, and review of this project.

\section{References}

1. Lindsay R, Hart DM, Aitken JM, MacDonald EB, Anderson JB, Clarke AC. Long-term prevention of postmenopausal osteoporosis by oestrogen. Evidence for an increased bone mass after delayed onset of oestrogen treatment. Lancet 1976;1:1038-41.

2. Ross RK, Paganini-Hill A, Mack TM, Arthur M, Henderson BE. Menopausal oestrogen therapy and protection from death from ischaemic heart disease. Lancet 1981;1:858-60.

3. Grodstein F, Stampfer MJ, Manson JE, Colditz GA, Willett WC, Rosner B, et al. Postmenopausal estrogen and progestin use and the risk of cardiovascular disease. N Engl J Med 1996;335:453-61.

4. Manolio TA, Furberg CD, Shemanski L, Psaty BM, O'Leary DH, Tracy RP, et al. Associations of postmenopausal estrogen use with cardiovascular disease and its risk factors in older women. The CHS Collaborative Research Group. Circulation 1993;88(5 Pt 1):2163-71.

5. Finucane FF, Madans JH, Bush TL, Wolf PH, Kleinman JC. Decreased risk of stroke among postmenopausal hormone users. Results from a national cohort. Arch Intern Med 1993;153:73-9.

6. Stampfer MJ, Colditz GA, Willett WC, Manson JE, Rosner B, Speizer FE, et al. Postmenopausal estrogen therapy and cardiovascular disease. Ten-year follow-up from the nurses' health study. $\mathrm{N}$ Engl J Med 1991;325:756-62.

7. Kampen DL, Sherwin BB. Estrogen use and verbal memory in healthy postmenopausal women. Obstet Gynecol 1994;83:979-83.

8. Ravnikar VA. Compliance with hormone therapy. Am J Obstet Gynecol 1987;156:1332-4.

9. Ferguson KJ, Hoegh C, Johnson S. Estrogen replacement therapy. A survey of women's knowledge and attitudes. Arch Intern Med 1989;149:133-6.

10. Handa VL, Landerman R, Hanlon JT, Harris T, Cohen HJ. Do older women use estrogen replacement? Data from the Duke Established Populations for Epidemiologic Studies of the Elderly (EPESE). J Am Geriatr Soc 1996;44:1-6. 